$\xi=-1$

\title{
Design and analysis of stepped reconfigurable rectangular patch antenna for LTE, vehicular and ultra wideband applications
}

\author{
M Ajay Babu, B T P Madhav, G. Bhargavi, V. Sai Krishna, Y. Hemanth Kumar Reddy, \\ G.V.S. Kalyan, M. Venkateswara Rao \\ Department of ECE, Koneru Lakshmaiah Education Foundation, AP, India \\ *Corresponding author E-mail: btpmadhav@kluniversity.in
}

\begin{abstract}
A stepped rectangular patch antenna having partial ground loaded with parasitic element is analyzed in this article. The Proposed antenna is connected to a diode on the flip side of the structure that is in between the parasitic element and the partial ground, the two cases ON, OFF are studied and analyzed. In OFF case the antenna got rejected at 3 bands ( 2 to $2.3 \mathrm{GHz}, 2.6$ to $3 \mathrm{GHz}$ and 5.8 to $7.9 \mathrm{GHz}$ ). On the other hand, in $\mathrm{ON}$ case antenna got rejected at single band (3.6 to $4.4 \mathrm{GHz}$ ). The maximum gain of $5.5 \mathrm{~dB}$ is observed at $7.8 \mathrm{GHz}$ frequency in $\mathrm{ON}$ case and the maximum gain of $4.4 \mathrm{~dB}$ is observed at $9 \mathrm{GHz}$ frequency in OFF case with an average gain of $3.3 \mathrm{~dB}$ in $\mathrm{ON}$ case and $2.9 \mathrm{~dB}$ in OFF case. The proposed antenna works in almost at all ultra wideband applications having single rejection at 3.6GHz4GHZ.The proposed antenna E-Field, Current distribution and radiation patterns have been analyzed using CST microwave studio in this article.
\end{abstract}

Keywords: Ultra wideband, Stepped rectangular patch.

\section{Introduction}

For Today's overwhelming information necessities the $4 \mathrm{G}$ standard LTE has been produced for high transmission capacity versatile access. So, utilizing this procedure reception apparatus can be outlined with wanted transfer speed for vehicular applications to get information. With the addition of new applications and technologies vehicular communications are expanding continuously. LTE remains for Long Term Evolution or 4GLTE provides high speed on move which can increase vehicle connectivity. Microstrip patch antennas are mostly used due to its ease of fabrication and integration on the skin of objects. The fabrication of LTE antenna using inkjet printer which is low cost process used for vehicular applications is reported in [1] and multi band antenna suitable for LTE is fabricated and it is folded to cylindrical form. The accuracy, speed and low cost of the inkjet printing is one of the main reason to use this technique for the fabrication of the LTE antenna in [2]. In [3] design of LTE antenna and its integration on roof top of an automobile using MID (molded interconnect device) technology has been reported. In [3] two different ultrabroadband antennas has been designed for navigation and mobile communication which can be integrated into the bodywork of a car. In [4] compact Dual band antenna for GSM 1800/1900/UMTS/LTE/UWB is designed for ultra-wide band applications with the frequency band of $3.1 \mathrm{GHz}$ to $10.6 \mathrm{GHz}$. Reconfigurable antennas are designed in [5-14]. Reconfigurable antenna changes the characteristics of the original antenna through mechanical, electrical or other means. For the implementation of is BAR-64 and Return loss of the antenna is observed and compared with base antenna with antenna connected to diode ON the reconfigurable antennas, several antenna structures are used, among them microstrip patch antennas are very attractive structures for reconfigurability of many types. In [15] a compact UWB frequency reconfigurable antenna using PIN diodes is designed. The OFF and ON states of the diode disables and enables various frequency band notches and hence reconfigurability in frequency is achieved. The different reconfigurable components are discussed in [16] which can modify the function and structure of the antennas. These reconfiguration techniques are based on the RFMEMS (Radio frequency microelectromechanical systems), PIN diodes [17-20], varactors, or by using material such as ferrites and liquid crystals. In this article a three-stepped rectangular patch antenna on a FR4 epoxy substrate is designed with a defective ground connected to a parasitic element which is on the either side of a substrate with a diode. The antenna is analyzed in diode on and off cases. The antenna is analyzed in commercially equipped tool CST Microwave studio 2017.

\section{Antenna Design}

An ultra-wide band antenna (UWB) has been designed initially with a three-stepped rectangular patch etched on the FR4 substrate with a defected ground and a parasitic element on the either side of the substrate and this element is connected to partial ground with a diode exactly in the middle achieving the reconfigurability

and OFF cases. The reconfigurable antenna has the added LTE band and the vehicular band with more resonance. The frequency 
shifting is observed due to the reconfigurability. The rectangular patch of size $\mathrm{P}$ (LP $x$ WP) is etched on the substrate of size $\mathrm{S}$ (LS $\mathrm{x}$ WS). The parasitic element has four elements of length L1, L2,
L3, L4. The ground plane of size G (LG x WG) is separated from the parasitic element by distance $d$. The antenna geometry is in figure 1 and its dimensions are mentioned in Table 1.

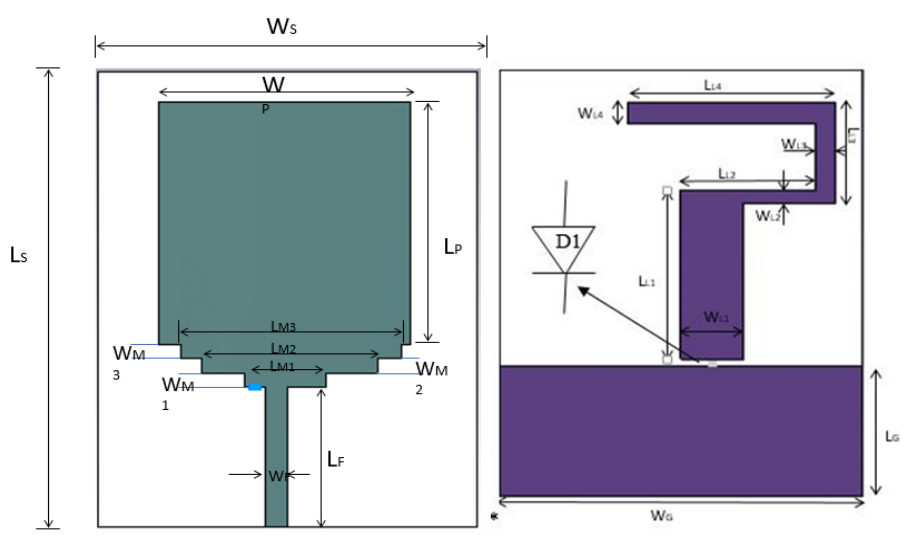

Figure 1: Design of the proposed Antenna

Table 1: Dimensions in $\mathrm{mm}$ of the antenna.

\begin{tabular}{|c|c|c|c|c|c|c|c|c|c|c|c|}
\hline $\mathrm{L}_{\mathrm{S}}$ & $\mathrm{W}_{\mathrm{S}}$ & $\mathrm{L}_{\mathrm{P}}$ & $\mathrm{W}_{\mathrm{P}}$ & $\mathrm{L}_{\mathrm{F}}$ & $\mathrm{W}_{\mathrm{F}}$ & $\mathrm{L}_{\mathrm{G}}$ & $\mathrm{W}_{\mathrm{G}}$ & $\mathrm{L}_{\mathrm{M} 1}$ & $\mathrm{~W}_{\mathrm{M} 1}$ & $\mathrm{~L}_{\mathrm{M} 2}$ & $\mathrm{~W}_{\mathrm{M} 2}$ \\
\hline 65 & 50 & 34.7 & 33.2 & 20 & 3 & 19.9 & 50 & 10.8 & 2 & 23.2 & 2 \\
\hline $\mathrm{L}_{\mathrm{M} 3}$ & $\mathrm{~W}_{\mathrm{M} 3}$ & $\mathrm{~L}_{\mathrm{L} 1}$ & $\mathrm{~W}_{\mathrm{L} 1}$ & $\mathrm{~L}_{\mathrm{L} 2}$ & $\mathrm{~W}_{\mathrm{L} 2}$ & $\mathrm{~L}_{\mathrm{L} 3}$ & $\mathrm{~W}_{\mathrm{L} 3}$ & $\mathrm{~L}_{\mathrm{L} 4}$ & $\mathrm{~W}_{\mathrm{L} 4}$ & $\mathrm{P}_{\mathrm{F}}$ & $\mathrm{d}$ \\
\hline 29.2 & 2 & 25.8 & 8.7 & 18.6 & 2 & 12.2 & 2.6 & 28.6 & 3.2 & 0.96 & 1 \\
\hline
\end{tabular}

\section{Discussion on Results}

The proposed antenna works in the ultrawideband region as shown in Figure 2 which works in both diode ON and OFF cases. In the diode on case the antenna works at $1.17 \mathrm{GHz}$ to $3.65 \mathrm{GHz}$ and $4.6 \mathrm{GHz}$ to beyond $12 \mathrm{GHz}$. In the diode off case the antenna works at $2.37 \mathrm{GHZ}$ to $2.63 \mathrm{GHz}, 2.94 \mathrm{GHz}$ to $5.83 \mathrm{GHz}$ and 7.41 $\mathrm{GHz}$ to beyond $12 \mathrm{GHz}$. The reflection characteristics of the antenna when there is no diode is also plotted. More resonance and frequency shifting is observed when the diode is placed.

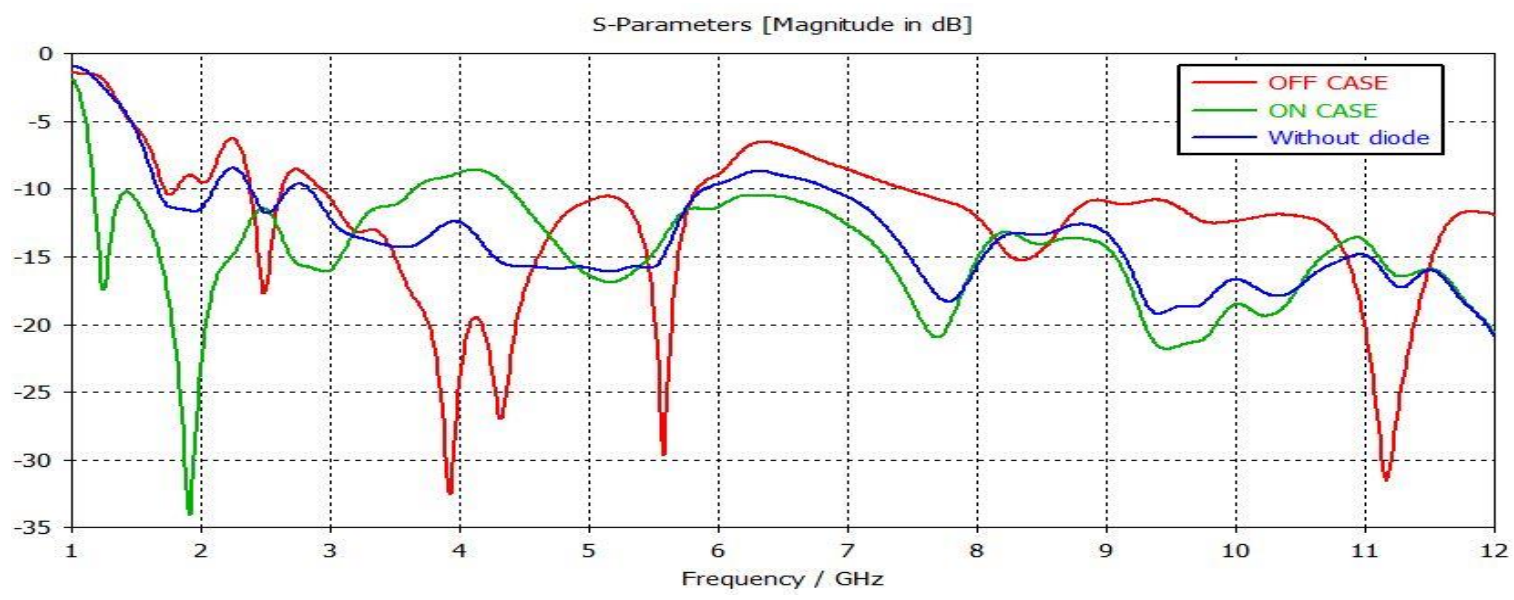

Figure 2: Return loss of stripped rectangular patch antenna with and without diode

Figure 3 shows the simulated results of the electric field distribution of the antenna at $2.48 \mathrm{GHz}, 3.92 \mathrm{GHz}, 5.57 \mathrm{GHz}$ frequencies in diode off case. Prefabrication studies of this antenna is done using CST Microwave studio. 


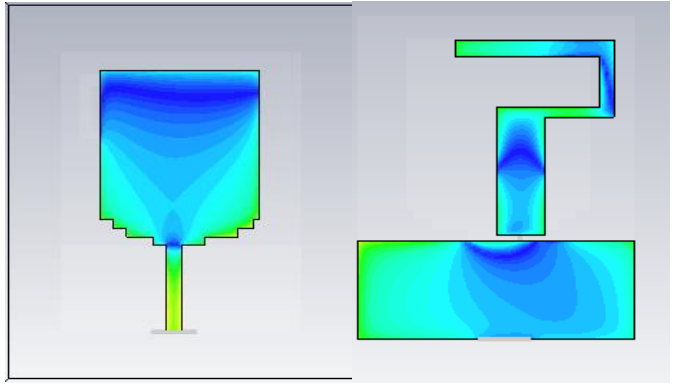

(a) $2.48 \mathrm{GHz}$
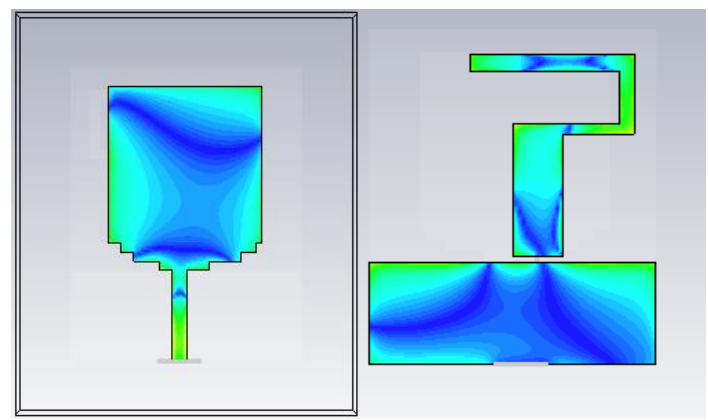

(b) $3.92 \mathrm{GHz}$
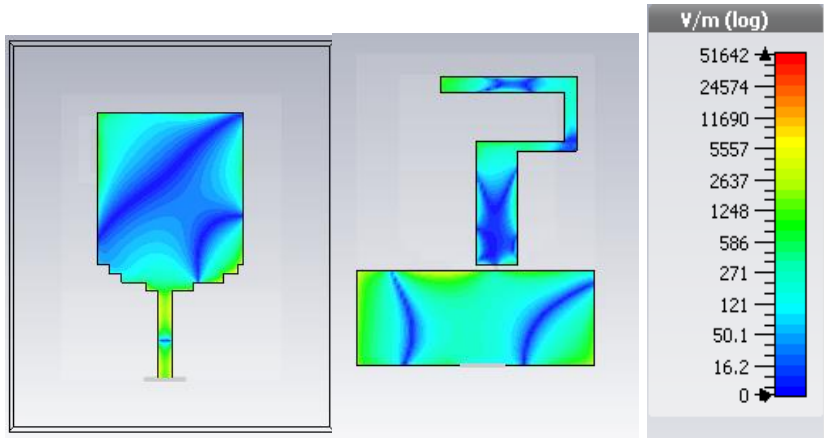

(c) $5.57 \mathrm{GHz}$

Figure 3: Simulated electric field distribution of the antenna at different frequencies in diode off case.

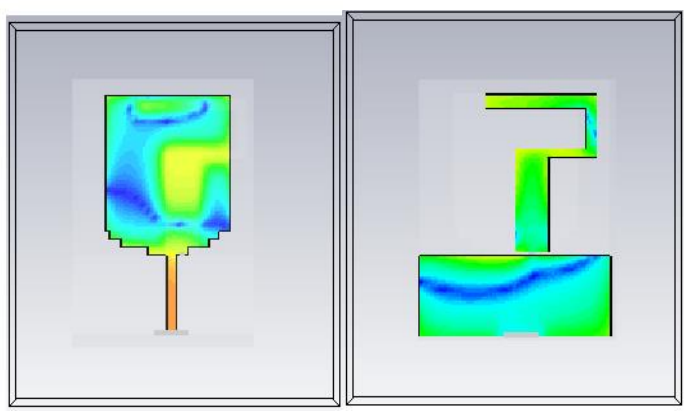

(a) $1.91 \mathrm{GHz}$

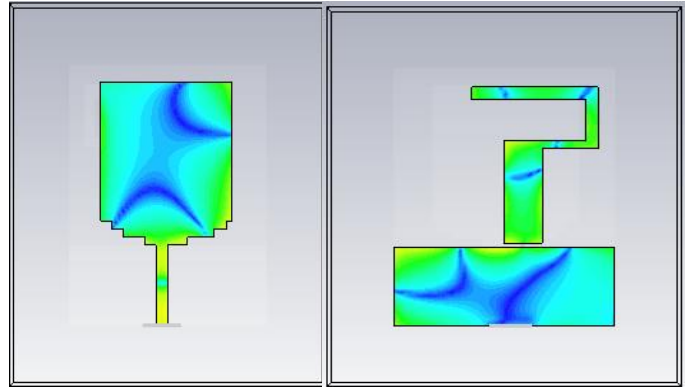

(b) $5.14 \mathrm{GHz}$
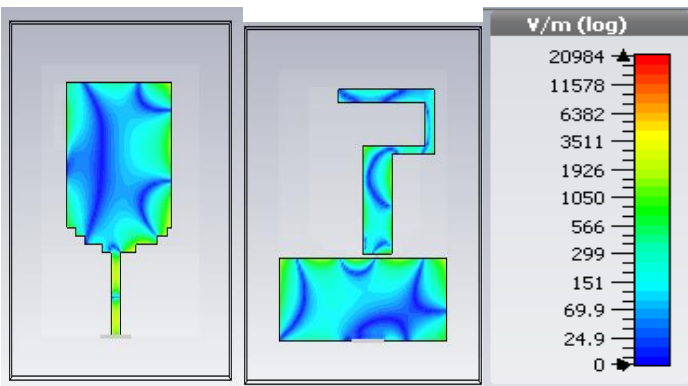

(c) $7.6 \mathrm{GHz}$

Figure 4: Simulated electric field distribution of the antenna at different frequencies in diode on case.

Figure 4 shows the simulated results of electric field distribution of antenna at $1.91 \mathrm{GHz}, 5.14 \mathrm{GHz}, 7.6 \mathrm{GHz}$ frequencies in diode on case. Figure 5 shows the simulated surface current of the antenna at $1.91 \mathrm{GHz}, 5.1 \mathrm{GHz}, 7.6 \mathrm{GHz}$ frequencies in diode on case The prefabrication studies of this antenna are done by using CST Microwave studio. The antenna has significant current at low frequency band that is at $1.9 \mathrm{GHz}$.
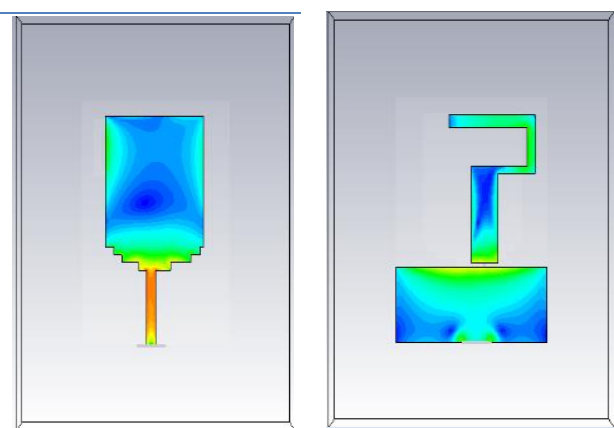

(a) 


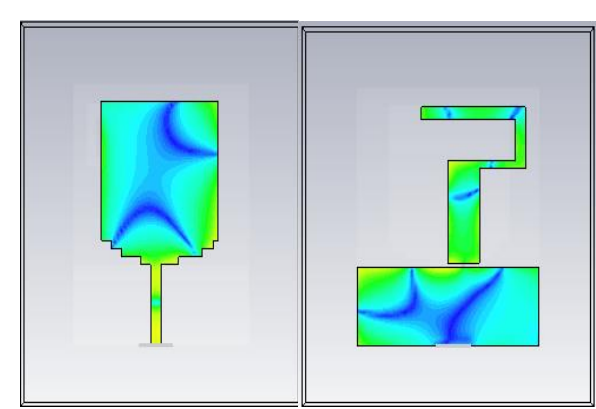

(b)
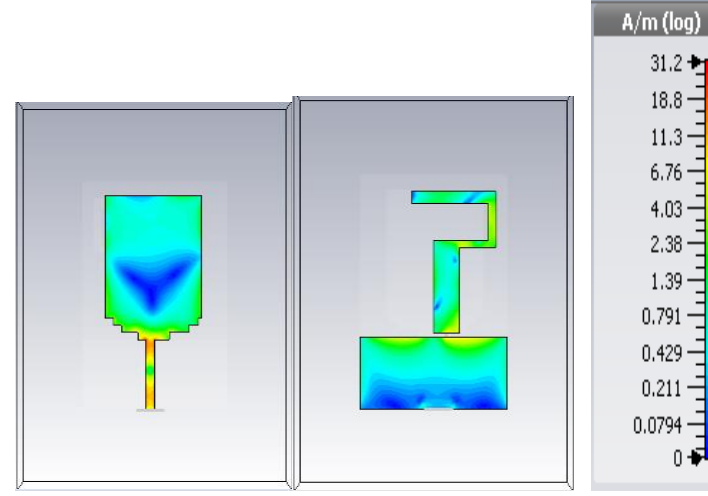

(c)

Figure 5: Simulate surface current of an antenna at the different frequencies (a) $1.9 \mathrm{GHz}$ (b) $5.1 \mathrm{GHz}$ (c) $7.6 \mathrm{GHz}$

Farfield Directivity Abs (Phi=90)

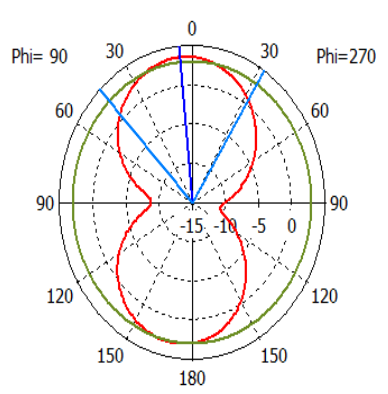

Theta / Degree vs. dBi

(a)

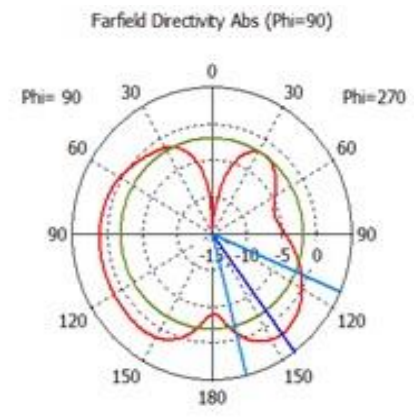

Theta / Degree vs. dBi

(c)
Farfield Directivity Abs (Phi $=90)$

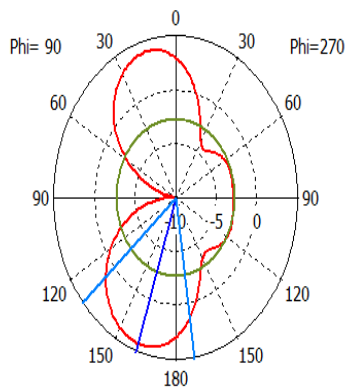

Theta / Degree vs. dBi

(b)

Farfield Directivity Abs (Theta $=90)$

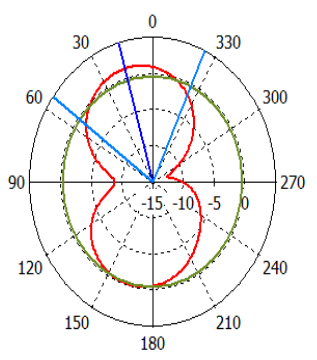

Phi / Degree vs. dBi

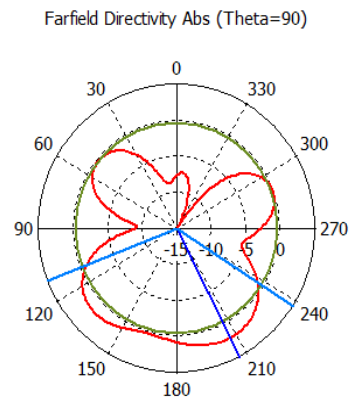

Phi / Degree vs. dBi
Farfield Directivity Abs (Theta $=90)$

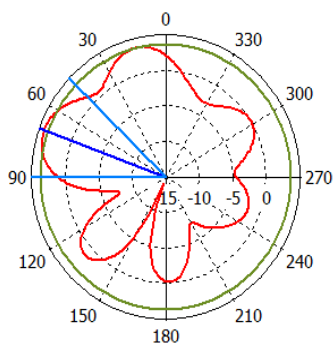

Phi / Degree vs. dBi

(c)

Figure 7: Simulated 2D radiation pattern at different frequencies (a) 1.91 $\mathrm{GHz}$ (b) $5.14 \mathrm{GHz}$ (c) $7.67 \mathrm{GHz}$ in diode off case

Figure 6 shows the radiation patterns of the antenna at the different frequencies $(2.48 \mathrm{GHz}, 3.92 \mathrm{GHz}, 5.57 \mathrm{GHz})$ at the diode off case. Figure 7 shows the radiation pattern of the antenna at the $1.91 \mathrm{GHz}, 5.14 \mathrm{GHz}, 7.67 \mathrm{GHz}$ frequencies at the diode on case. Farfield Directivity Abs (Theta $=90$ ) Farfield Directivity Abs (Theta $=90$ )

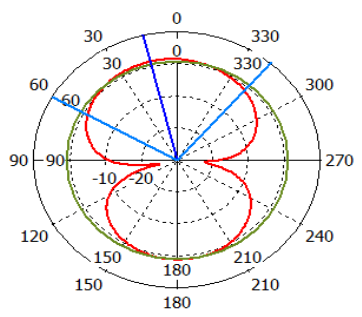

Phi / Degree vs. dBi

(a)

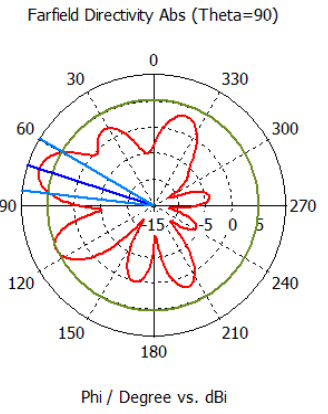

(c)

Farfield Directivity Abs (Phi $=90)$

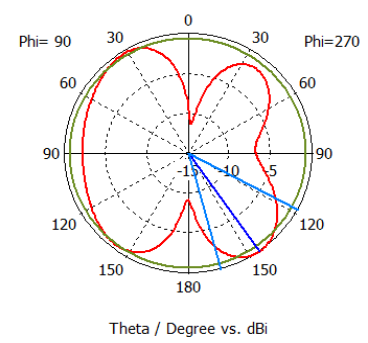

(b)

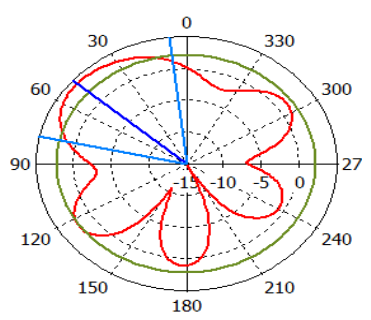

Phi / Degree vs. dBi

(b)

Farfield Directivity Abs (Phi=90)

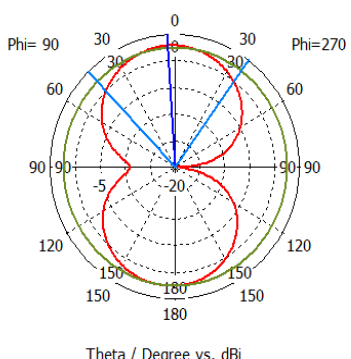

(a)

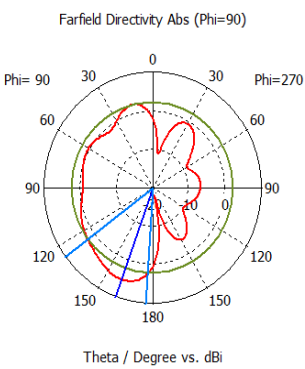

(c)

Figure 7: Simulated 2D radiation pattern at different frequencies (a) $1.91 \mathrm{GHz}$ (b) $5.14 \mathrm{GHz}$ (c) $7.67 \mathrm{GHz}$ in diode on case 
The gain with different frequencies and the 3D gain pattern of the antenna is observed at different frequencies that is $1.91 \mathrm{GHz}, 5.14 \mathrm{GHz}, 7.6 \mathrm{GHz}$ in diode on case.

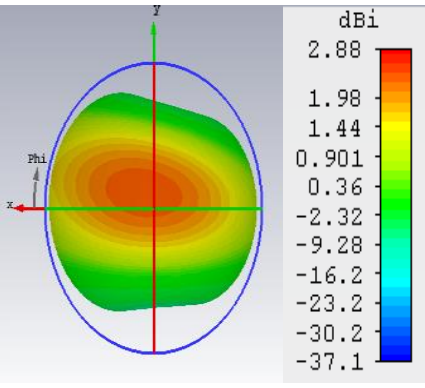

(a)

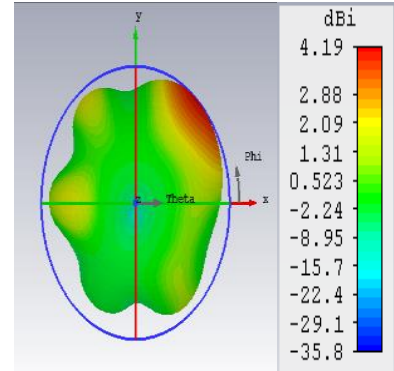

(b)

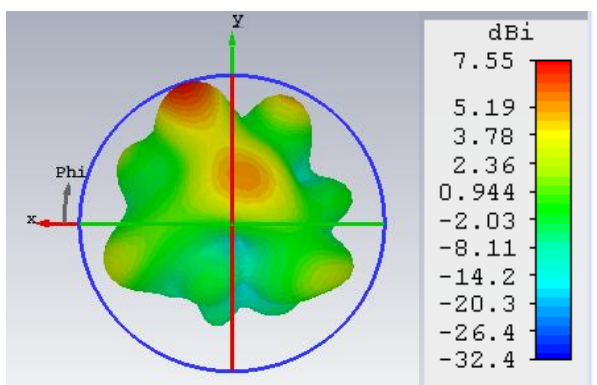

(c)

Figure 8: Gain at different frequencies (a) $1.91 \mathrm{GHz}$ (b) $5.14 \mathrm{GHz}$ (c) 7.67 $\mathrm{GHz}$ in diode on case.

Figure 9 shows the maximum gain vs frequency curve. It is observed that the gain is maximum in diode on case than in diode off case. The maximum gain of $5.5 \mathrm{~dB}$ is observed in diode on case at $7.8 \mathrm{GHz}$ frequency. The maximum gain of $4.4 \mathrm{~dB}$ is observed in diode off case at $9 \mathrm{GHz}$ frequency.

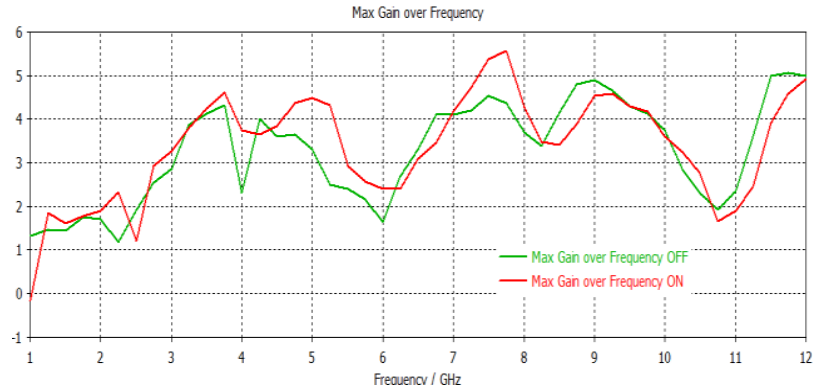

Figure 9: Maximum gain vs. frequency in ON case and OFF case

\section{Parametric Study}

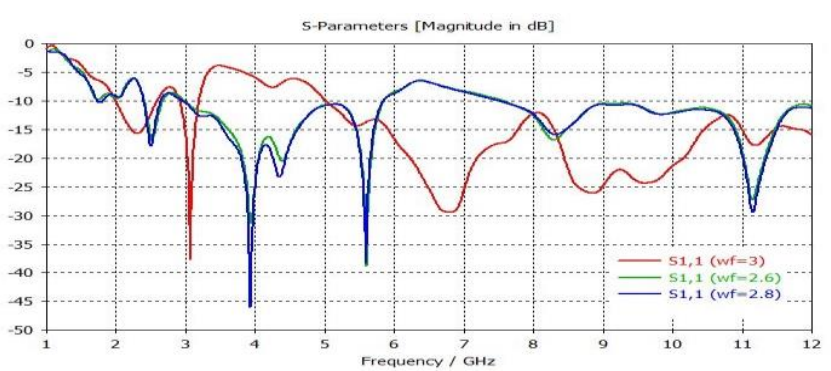

Figure 10: parametric study of proposed antenna by varying width of the feed.

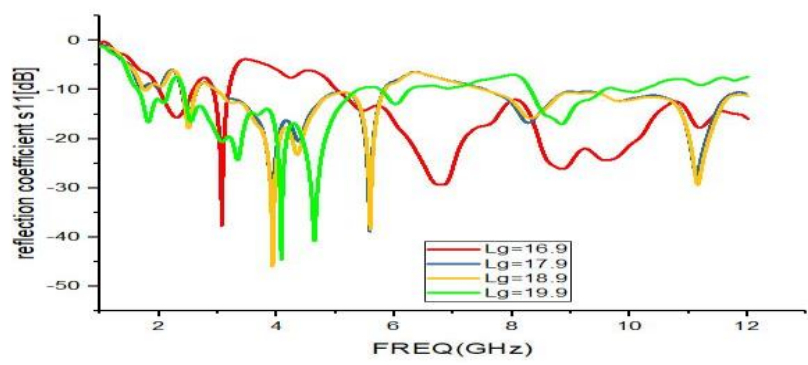

Figure 11: Parametric study of proposed antenna by varying length of the feed

\section{Conclusion}

A stepped reconfigurable antenna is analyzed and discussed in this article. CST microwave suite 2017 is used to analyze and characterize the results of the proposed antenna. Two cases that is ON and OFF cases have been studied and characteristics has been discussed. The proposed antenna when stimulated in $\mathrm{ON}$ cases works at almost ultrawideband region having single rejection at $3.6 \mathrm{GHz}-4 \mathrm{GHz}$ where as in OFF case three rejections have been occurred. The propose antenna gain plots and efficiency of the antenna have been analyzed in this article.

\section{Acknowledgements}

The authors deeply express their gratitude to ALRC Research Centre, Department of ECE, K L University for their encouragement during this work. Further, we express our gratitude to DST through ECR/2016/000569, FIST SR/FST/ETI-316/2012 and $\mathrm{EEQ} / 2016 / 000604$.

\section{References}

[1] Gschwendtner, E., \& Wiesbeck, W. (2003) Ultra-Broadband Car Antennas for Communications and Navigation Applications. IEEE Transactions on Antennas and Propagation, 51(8), pp 2020-2027.

[2] D. Sreenivasa Rao, J. Lakshmi Narayana. (2016) Microstrip Parasitic Strip Loaded Reconfigurable Monopole Antenna, ARPN Journal of Engineering and Applied Sciences, ISSN: 1819-6608 Vol. 11, No. 19, pp 1-7.

[3] Haupt, R. L., \& Lanagan, M. (2013) Reconfigurable Antennas. IEEE Antennas and Propagation Magazine, 55(1), pp 49-61.

[4] Wang, B. Z., Xiao, S., \& Wang, J. (2007) Reconfigurable PatchAntenna Design for Wideband Wireless Communication Systems. IET Microwaves, Antennas \& Propagation, 1(2), pp 414419.

[5] D. Sreenivas Rao, K. Supraja, K. (2017) Nematic Phase Liquid Crystal Material Based Double-Dipole Reconfigurable Antenna, Rasayan Journal of Chemistry, ISSN: 0974-1496, Vol 10, No 3, pp 866-872.

[6] M. Ajay Babu, B. Mohan Reddy, R. Divya Chaitanya, T. Satish and T. Anilkumar. (2017) A Dual-Polarization Reconfigurable Antenna with Beam Switching Characteristics For S-Band Applications, ARPN Journal of Engineering and Applied Sciences, ISSN 1819-6608, Vol. 12, No. 16, pp 4841-4847.

[7] Kosuru Murthy, Kodidasu Umakantham, Korlapati Satyanarayana Murthy. (2017) Reconfigurable Notch Band Monopole Slot Antenna for WLAN/IEEE-802.11n Applications, International Journal of Intelligent Engineering and Systems, ISSN: 21853118, Vol 10, No 6, pp 166-173.

[8] T V Ramakrishna, N Kiran, B Sravani, N Vamsi and K L Yamini. (2017) Frequency Reconfigurable Antenna for Ku-Band Applications, ARPN Journal of Engineering and Applied Sciences, ISSN: 1819-6608, Vol. 12, No. 22, pp 6527-6532.

[9] G Jyothsna Devi. (2017) Reconfigurable Mimo Antenna For 5G Communication Applications, International Journal of Pure and Applied Mathematics, Vol 117, No. 18, pp 89-95.

[10] U Ramya, M Ajay Babu, M Venkateswara Rao. (2017) Double Notch Reconfigurable Monopole Antenna with Stub Loaded 
DGS, International Journal of Pure and Applied Mathematics, Vol 117, No. 18, pp 97-103

[11] M. Ajay Babu, P. Farhana Banu, G. Harsha Sai Teja, P. Prashanth, K. L. Yamini. (2018) Octagonal Shaped Frequency Reconfigurable Antenna for Wi-Fi and Wi-MAX Applications, Lecture Notes in Electrical Engineering, ISSN: 1876-1100, Vol 471, pp 581-588, doi.org/10.1007/978-981-10-7329-8_59.

[12] D. Sreenivasa Rao, G. Lalitha, S. Mohammad Parvez, J. Naveen, D. Mani Deepak, A. N. Meena Kumari. (2018) A Frequency Reconfigurable Spiral F-Shaped Antenna for Multiple Mobile Applications, Lecture Notes in Electrical Engineering, ISSN: 18761100, Vol 471, pp 571-580, doi.org/10.1007/978-981-10-7329858.

[13] B T P Madhav, T Venkateswara rao, T Anil Kumar. (2018) Design of 4-Element Printed Array Antenna for Ultra-Wideband Applications, International Journal of Microwave and Optical Technology, Vol.13, No.1, pp 8-17.

[14] A Manikanta Prasanth, Sreeramineni Prasanth, Batchu Mohan Sai Krishna, Devani Manikantha, Usirika Sharmila NagaSai. (2015) "Analysis of Defected Ground Structure Notched Monopole Antenna", ARPN Journal of Engineering and Applied Sciences, ISSN 1819-6608, Vol. 10, No. 2, pp 747-752.

[15] S S Mohan Reddy, P Mallikarjuna rao. (2015) Asymmetric Defected Ground Structured Monopole Antenna for Wideband Communication Systems, International Journal of Communications Antenna and Propagation, ISSN: 2039-5086, Vol 5, Issue 5, pp 256-262.

[16] Mounika Sanikommu, M. N. V. S. Pranoop, K. S. N. Manikanta Chandra Bose and B. Sriram Kumar, CPW Fed Antenna for Wideband Applications based on Tapered Step Ground and EBG Structure, Indian Journal of Science and Technology, ISSN: 0974-6846, Vol 8, Issue 9, May 2015, pp 119-127.

[17] K V V Kumar, A V Manjusha, P Ram Bhupal Chowdary, L Sneha, P Renu Kantham. (2014) "Analysis of CPW Fed Step Serrated Ultra Wide Band Antenna on Rogers RT/Duroid Substrates", International Journal of Applied Engineering Research, ISSN 0973-4562, Volume 9, Number 1, pp. 53-58.

[18] B.T.P.Madhav, S. S. Mohan Reddy, Bandi Sanjay, D.Ujwala (2013) "Trident Shaped Ultra Wideband Antenna Analysis based on Substrate Permittivity", International Journal of Applied Engineering Research, ISSN 0973-4562, Volume 8, Number 12, pp. 1355-1361.

[19] Krishnam Naidu Yedla, G.S., Kumar, K.V.V., Rahul, R. (2014) "Fractal aperture EBG ground structured dual band planar slot antenna", International Journal of Applied Engineering Research, ISSN 0973-4562, Volume 9, Number 5, pp 515-524.

[20] P.Lakshmikanth, Kh Takeshore. (2015) Printed Log Periodic dipole antenna with Notched filter at $2.45 \mathrm{GHz}$ Frequency for wireless communication applications, Journal of Engineering and Applied Sciences, ISSN: 1816-949X, Vol 10, Issue 3, pp 40-44. 